\title{
Climate change in China and China's policies and actions for addressing climate change
}

\author{
D. Qin ${ }^{1}$, J. Huang ${ }^{2}$, and Y. Luo ${ }^{3}$
}

1 State Key Laboratory of Cryospheric Sciences, Cold and Arid Regions Environmental and Engineering Research Institute, Chinese Academy of Sciences, Lanzhou, Gansu, China 730000 China Meteorological Administration, Beijing, China 100081

2 School of Physics, Peking University, Beijing, China 100871

3 National Climate Center, China Meteorological Administration, Beijing, China 100081

\begin{abstract}
Since the first assessment report (FAR) of Inter-Governmental Panel on Climate Change (IPCC) in 1990, the international scientific community has made substantial progresses in climate change sciences. Changes in components of climate system, including the atmosphere, oceans and cryosphere, indicate that global warming is unequivocal. Instrumental records demonstrate that the global mean temperature has a significant increasing trend during the $20^{\text {th }}$ century and in the latest 50 years the warming become faster. In the meantime, the global sea level has a strong increasing trend, as well as the snow coverage of Northern Hemisphere showed an obvious downward trend. Moreover, the global warming plays a key role in significantly affecting the climate system and social-economy on both global and regional scales, such as sea level rise, melting of mountain glaciers and ice sheets, desertification, deforestation, increase of weather extremes (typhoon, hurricane and rainstorm) and so on. The state of the art understanding of IPCC Fourth Assessment Report (AR4) was most of the observed increase in global average temperatures since the mid- $20^{\text {th }}$ century is very likely due to the observed increase in the concentrations of anthropogenic greenhouse gases.

Climate change issues, as a grave challenge to the sustainable development of the human society, have received ever greater attention from the international community. Deeply cognizant of the complexity and extensive influence of these issues and fully aware of the arduousness and urgency of the task of addressing climate change, the Chinese government is determined to address climate change in the process of pursuing sustainable development. The facts of climate change in China and its impacts, and China's policies and actions for addressing climate change are introduced in this paper.
\end{abstract}

\section{The climate change in China}

China locates in the southeastern part of the Eurasian Continent, the largest continent in the world and lies to the west of the Pacific, the world's largest ocean. Due to its great interior extent, the climate of China is dominated by totally different dry continental and wet monsoon climate. The geographic feature of the high topography in the west and the low relief in the east of China favors the features that most parts of the country have a seasonal precipitation and temperature variations that is noticeably larger than other continental regions at the same latitude over Northern Hemisphere.

This is an Open Access article distributed under the terms of the Creative Commons Attribution-Noncommercial License 3.0, which permits unrestricted use, distribution, and reproduction in any noncommercial medium, provided the original work is properly cited. 


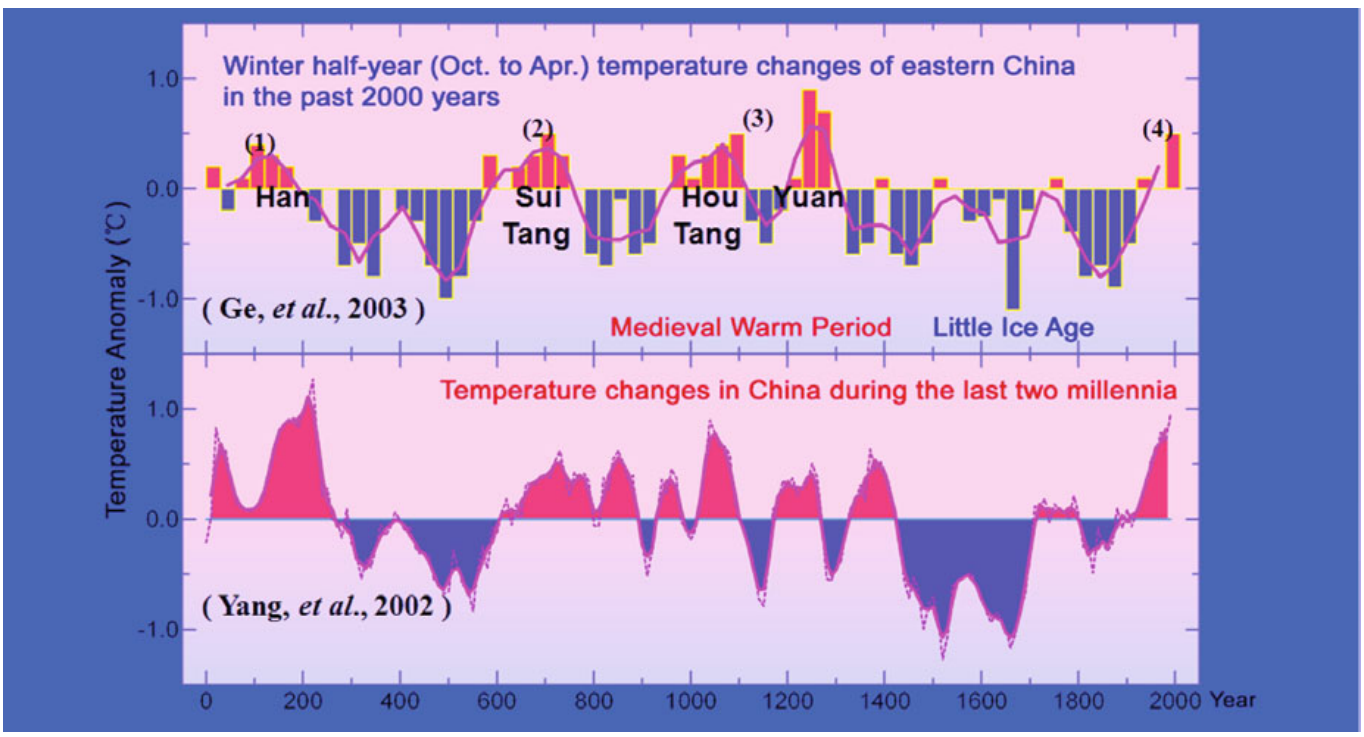

Fig. 1. Wintertime temperature changes of Eastern China (top; From Ge et al., 2003) and temperature changes in China (bottom; From Yang et al., 2002) during the past 2000 years.

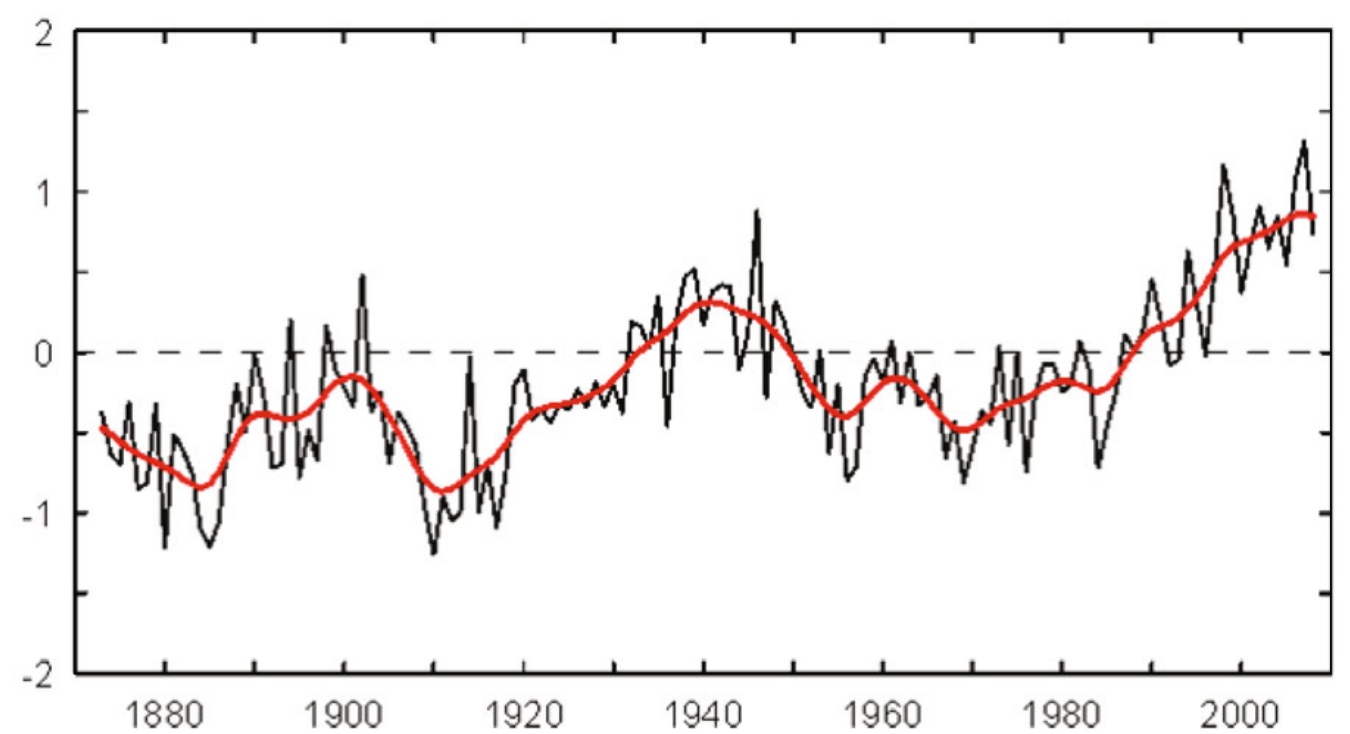

Fig. 2. Annual mean temperature anomalies in China during $1873-2008\left({ }^{\circ} \mathrm{C}\right.$, relative to $1971-2000$. Updated from Wang et al., 1998).

During the past 2000 years, there were at least four warm periods in China: (1)1-200 AD; (2) 570-780 AD; (3)930-1320 AD; and (4) 1920 AD-present, as shown in Fig. 1. From 1873 to 2008, the climate warming trends observed in China was basically the same as the globe, with the changing rate as $0.5-0.8^{\circ} \mathrm{C} / 100$ a (Fig. 2).

The latest observational records published by China Meteorological Administration show that China has registered a raised mean temperature by $1.3^{\circ} \mathrm{C}$ in the past 58 years (1951-2008). In particular, the annual averaged air temperature in 2007 made the warmest record since 1951, when China started its systematic meteorological measurement. Another significant feature of climate change in 


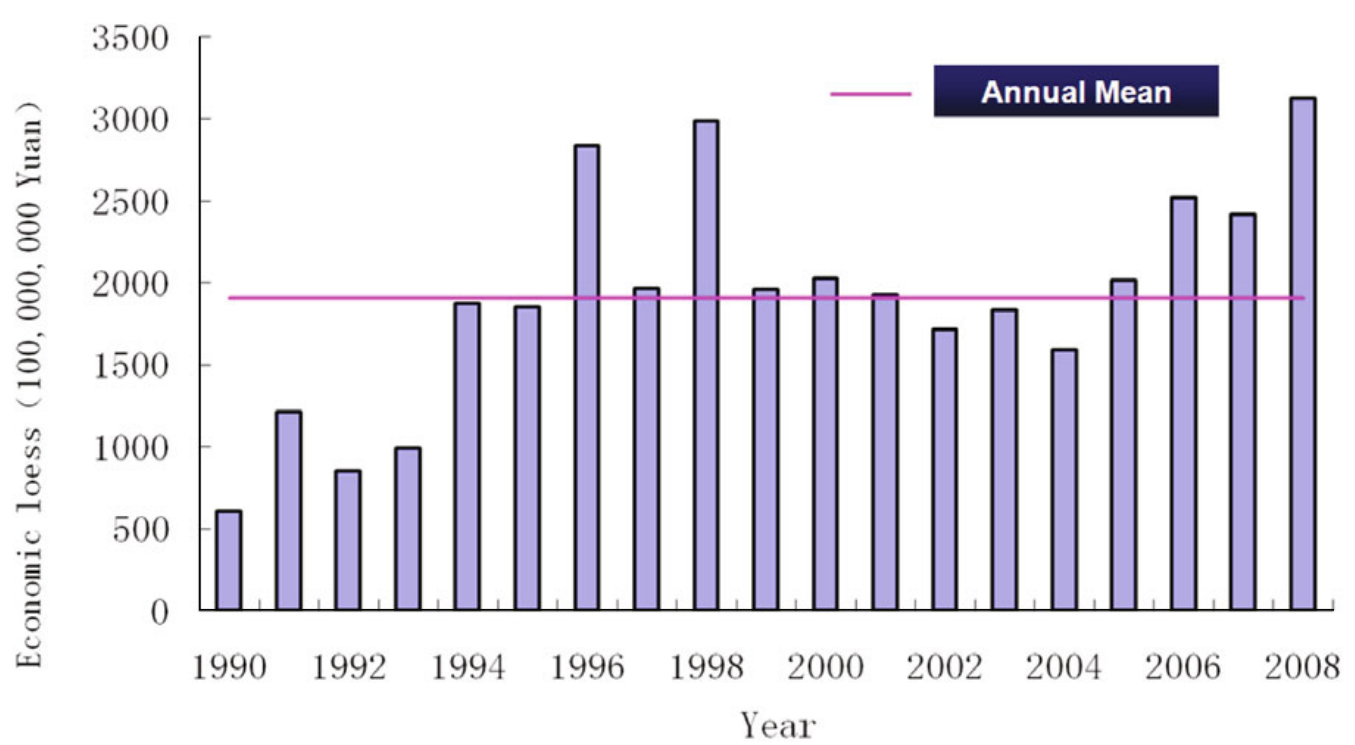

Fig. 3. The economic losses caused by meteorological disasters in China from 1990 to 2008. The annual averaged economic loses from 1990 to 2006 is 181 billion Chinese Yuan.

China during the instrumental era was the precipitation variation during the past 50 years. The distribution of precipitation has been notably changed in patterns with more rainfall in the west and south, and less in the north and northeast.

Along with the global warming, instrumental records show that extreme climate events, including heat waves, droughts, and heavy rainfall, have experienced an ascending trend in terms of both frequency and intensity. People have seen more undesired climate events, including heat waves in the summer, extended local droughts, especially in the north, heavy rainfall in the south, and snowfall in the west. These extremes led to serious meteorological disasters, which caused a huge economic losses to China (Fig. 3), reported by China Meteorological Administration. In addition, studies show that China is likely to have a warmer climate in the future. By 2020, China may have an increased mean temperature by $1.3-2.1^{\circ} \mathrm{C}$ and by $2.3-3.3^{\circ} \mathrm{C}$ in 2050 (Qin et al., 2005). Furthermore, increased occurrences of extreme weather and climate events are expected in the future.

\section{The impacts of climate change on China}

The climate change has played an important role in affecting various aspects of China, such as agriculture and industry, natural resources and ecosystem, economy and society. The studies show that the impacts of the future climate change on farming and animal raising activities in China will largely be negative in nature. Three major crops, wheat, rice and corn, will experience a reduction in the yield. By 2030 , China's crop growing capacity may go down by $5 \%-10 \%$ as the result of climate warming. In the aspect of water resources, climate change has altered the distribution of water resources in China. In the past 20 years, major rivers in the north, including Yellow River, Huaihe River, Haihe River, and Liaohe River, have noticeably reduced their water resources, though the river runoff in the south has increased. With the global warming, the accelerated melting of glaciers and snow cover threaten the oasis ecosystems in the west China. In the past 50 years, the area of glaciers in the northwest part of the country has dwindled by $21 \%$. Meanwhile, the frozen earth layer of the permafrost in Tibet has thinned by 4 to $5 \mathrm{~m}$. Vegetation typically grown in the subtropical and temperate regions in the east are migrating further north with an extended phenological period. Climate change may increase disease attacks and associated propagation, endangering human health. It may increase the probability of geological and meteorological disasters, imposing serious threats to engineering 
projects. Climate change affects the ecological environment and biodiversity in the nature conservation zones and national parks, which in turn affects natural resources availability and tourism. In addition, it may endanger people's lives and properties, posing a threat to the living standard and social stability.

\section{China's policies and actions for addressing climate change}

At end of 2008, mainland China has registered a population of 1.328 billion, $20 \%$ of the world's population. As the largest developing country, China is now at the intermediate stage of industrialization, urbanization, and modernization and in a crucial period in building up a moderately prosperous society in all aspects. China needs a rational growth of energy consumption so as to reach the desired development goals. In China, coal dominates energy consumption, which will not see a fundamental change for a long period of time in the future. As a result, curbing GHGs emission will be a tough task for China.

However, in order to deal with climate change impacts, China will stick to the following principles: (1) Addressing the climate change issue under the framework of sustainable development; (2) Common but differential obligations; (3) Mitigation and adaptation on the same footing; (4) Framework Convention on Climate Change and Kyoto Protocol are the major channels for climate change impact adaptation; (5) S\&T innovation and technology transfer; (6) Broad participation and extensive international cooperation.

Many important measures already have been carried out in China to mitigate the effect of anthropogenic activity on climate, such as elimination of outdated production capacity. During the period of 2006-2008, China shut down small coal-fired power plants worth 34.21 million kilowatts, and washed out outdated iron and steel plants with a capacity of 60.59 million tons for iron, and 43.47 million tons for steel. The closing-down has led to a reduced output of cement, iron alloy, calcium carbide, and coke by 140 million tons, 2.46 million tons, 2.44 million tons, and 64.45 million tons respectively. In the meantime, the government encourages developing clear and renewable energy with great efforts, such as wind and hydraulic power, solar energy and nuclear power.

Additionally, scientific research and R\&D activities are strengthened. During the period 2001-2005, the country has made an appropriation worth of RMB 2.5 billion for climate change studies through the National Key Technologies Program, National 863 Program, and National 973 Program. International cooperation on climate change is also encouraged. China encourages the public participating in the area of climate change, with an emphasis on raising the public awareness of climate change and associated adaptation capability, and creating an agreeable environment for such adaptation. Now, people have started to change their lifestyles and try to save energy and reduce emissions in their daily life.

In the years ahead, China will further integrate actions on climate change into its economic and social development plan and take the following measures: First, China will intensify effort to conserve energy and improve energy efficiency. China will endeavor to cut carbon dioxide emissions per unit of GDP by a notable margin, 40\% - 45\%, by 2020 from the 2005 level. Second, China will vigorously develop renewable energy and nuclear energy and will endeavor to increase the share of non-fossil fuels in primary energy consumption to around $15 \%$ by 2020 . Third, Chinese government will energetically increase forest carbon sink and will endeavor to increase forest coverage by 40 million hectares and forest stock volume by 1.3 billion cubic meters by 2020 from the 2005 levels. Fourth, China will step up effort to develop green economy, low-carbon economy and circular economy, and enhance research, development and dissemination of climate-friendly technologies.

\section{References}

1. Ge Q.S, Zheng, J.Y., Fang, X.Q., Man, Z.M., Zhang, X.Q., Wang, W.C., Winter half-year temperature reconstruction for the middle and lower reaches of the Yellow River and Yangtze River, China, during the past 2000 years. The Holocene, 2003. 13(6), 933-940. 
2. Yang B, Bräuning A, Johnson KR, Shi YF. General characteristics of temperature variation in China during the last two millennia. Geophysical Research Letters, 2002, DOI: 10.1029/ 2001GLQ14485, 29(9).

3. Wang SW, Ye JL, Gong DY, et al., 1998: Construction of mean annual temperature series for the last one hundred year in China. Quarterly Journal of Appl Met., 9(4): 392-401.

4. Qin D. H., Ding Y. H., Su J. L., et al., 2005: Assessment of climate and environment changes in China (I): Climate and environment changes in China and their projection. Adv. Clim. Change Res., 1(1): 4-9. 